\title{
Modelling of Photovoltaic Water Pumping System Based on Artificial Intelligence
}

\author{
Mensia Nawel $^{1 *}$, Talbi Mourad ${ }^{2}$, Bouaïcha Mongi ${ }^{1}$ \\ ${ }^{1}$ Photovoltaic Laboratory, Center of Researches and Technologies of Energy of Borj Cedria, Borj Cedria B.P N 952050 - \\ Hammam Lif, Tunisia \\ ${ }^{2}$ Laboratory of Semiconductors, Nanostructures and Advanced Technology, Center of Researches and Technologies of Energy \\ of Borj Cedria, Borj Cedria B.P N 952050 - Hammam Lif, Tunisia
}

Corresponding Author Email: mensia_nawel@hotmail.com

https://doi.org/10.18280/ama_b.620102

Received: 28 October 2018

Accepted: 27 January 2019

\section{Keywords:}

convex polytopic transformation, vertex matrixes, extreme values, temperature, insolation, multi-model approach, photovoltaic system

\begin{abstract}
In this work, we develop and simulate an accurate model of a gird connected photovoltaic (PV) system composed by a PV generator, a buck converter and a motor-driven pump. The purpose of this study is to represent closely the system behavior under different climatic conditions (temperature and insolation), without using any order reduction technique and without identifying the operating point. The proposed modeling method is based on the multi-model technique for representing the PV system by a set of simple models. Those latters are derived from a polytopic transformation of premises that represent non-constant variables in PV system state equations. Every premise is bounded by two extreme values depending on temperature and insolation. Each model is associated to an activate function which estimates the model contribution in the global functioning of the system. The combination of all these models builds a flexible model which can accurately describe the behavior of the PV system. The simulation results prove that the obtained model can reproduce with high precision the conduct of the system state variables under different conditions (temperature and insolation). This model permits to develop an intelligent law of control to effectively attain Maximum Power Point (MPP) in a PV system.
\end{abstract}

\section{INTRODUCTION}

Traditional energy sources are not able to meet the growing demand for energy worldwide. Therefore, alternative energy sources like biomass, sunlight and wind, come into mentality. In this context, photovoltaic energy presents a source of attractive energy; it is non-polluting, sustainable and renewable. Today, photovoltaic energy is increasingly used in various terrestrial applications such as lightning, water pumping and telecommunication [1-2]. Though, its exploitation is less than conventional energy sources due to the high cost and the low efficiency of photovoltaic systems. The rational employment of solar energy imposes the MPP tracking of Photovoltaic Generators (PVGs) and estimation of the produced energy.

The exact identification of MPP is closely related to the efficiency of controller that provides it. Today, intelligent controllers are among the most powerful and robust controllers. Their synthesis is based on a model of system to command. Consequentially, it is necessary to have flexible and reliable model of the photovoltaic system, in order to perform an intelligent command for getting its performance as maximum as possible.

In literature, many techniques have been proposed for modeling and simulating (PVG) based on diode model. Although, a great number of this techniques are based on the adjustment of the curve $\mathrm{I}(\mathrm{V})$ at the points of the experimental curve, which requires the graphic extraction of curve slope at determined points or require an experimental analysis of photovoltaic device. These techniques have drawbacks, for the experimental curves $\mathrm{I}(\mathrm{V})$ are not permanently accessible in manufacturers' data sheets, and devices for measurement of experimental data are not usually available as well. Others modeling techniques based on the modification of the electronic characteristic of a diode model of photovoltaic cell [3]. The model resulting from these techniques does not precisely reflect the real system behavior. Others research works proposed techniques of modeling tools based on the adjustment of the curve $P(V)$. Although, this latter is based only on the characteristic $I(V)$ and the peak power of the resulting model is not always peak power of the real device. Also, there are few modeling studies based on artificial intelligence such as multi-model approach [4]. These studies are confronted with the problem of determination of PV system operating points for constructing the model base.

This problem is overcoming in this work by extracting a basis of eight linear models from a convex polytopic transformation of scalar functions origin of nonlinearity in the system state equations. Linear basis models are calculated according to the extreme values of temperature and insolation, and the nonlinearity of the global system is rejected in the weighting functions. A flexible model which can accurately describe the behavior of the PV system is provided by combination of models assigned by the weighting functions. Consequently the PV system model is obtained without use of an order reduction technique which causes an information loss, and without requirement of the functioning point identification.

The rest of this paper is organized as follow: in section 2 , is presented the photovoltaic pumping system to be study. Its model state, is given in section 3 . The elaboration of the multi- 
model representation of the system is detailed in section 4. In section 5, are given the simulation results and interpretations. Finally, the conclusion and perspectives are given in section 6 .

\section{STUDY OF THE PHOTOVOLTAIC PUMPING SYSTEM}

A photovoltaic pumping system is generally composed by a photovoltaic generator, a motor-driven pump and a water tank to ensure the continuity of the supply when solar energy is not sufficient. Two types of systems can be used. In the first type, the Photovoltaic Generator (PVG) is directly coupled to the motor-driving pump. In the second type the PVG can be coupled either to an AC motor-driven pump through a DC-DC converter connected to a DC-AC converter [5], or to a DC motor-driven pump through a DC-DC converter. The latter type is the subject of our interest; indeed we will be modeling the photovoltaic system consists of a PV generator coupled to a DC permanent magnet motor through a buck convertor which equivalent circuit diagram is the following:

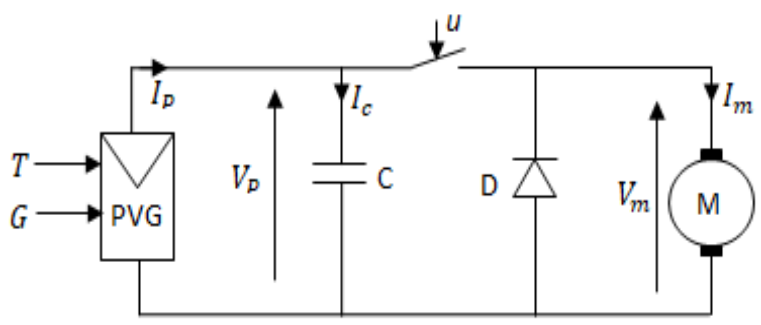

Figure 1. Electrical diagram of water pumping photovoltaic system

It's consisted of the following components:

- $\quad$ Photovoltaic Generator (PVG):

The PVG consist of $N p$ arrays connected in parallel. Each array is composed of np panels associated in series, and each panel is formed of nc cells related in series. Therefore, the array is composed by $N s=n p \times n c$ cells. So, if the cell current is Ipvc and its voltage is $V p v c$ then the PVG current and voltage are successively: $I p=N p I p v c$ and $V p=$ NsVpvc.

- $\quad$ Buck converter:

The chopper is controlled by the switched control variable $\mathrm{u}$ and its input is connected to the capacitor $C$, which allows transforming the current source $I p$ to a voltage source $V p$.

- The Diode:

The diode ensures continuity of the current in the motor at the moment of disconnecting power to avoid peak overvoltage.

- The motor-driven pump:

we consider a DC permanent magnet motor with Constant flux, where the armature reaction and the switching phenomenon are assumed to be negligible.

\section{STATE MODEL OF THE PHOTOVOLTAIC PUMPING SYSTEM}

The electrical behavior of a PV cell can be described with good accuracy by the single diode equivalent circuit [6]. The ideal equivalent circuit is a current source in parallel with a single-diode which governed by the following equation:

$$
I_{p v c}=I_{p h c}-I_{s d}\left(\exp \left(\frac{q V_{p v c}}{K n T_{C}}\right)-1\right)
$$

where:

$I_{p v c}:$ PV cell current,

$I_{p h c}:$ Light current,

$I_{s d}$ : Diode reverse saturation current,

$V_{p v c}:$ PV cell voltage,

$q=1.6 .10-19 C$, is telectron charge,

$K=1.38 \cdot 10-23 \mathrm{~J} / K$, is the Boltzmann's constant,

$n$ is the ideal factor,

$T_{c}$ : the actual cell temperature.

From the last equation, we can deduce the expression of the PVG output current $I_{P}$ according to its voltage $V_{P}$ :

$$
I_{p}=N_{P} I_{p h c}-N_{p} I_{s d}\left(\exp \left(\frac{q V_{p}}{N_{S} K n T_{C}}\right)-1\right)
$$

If we consider: $I_{p h}=N_{p} I_{p h c}$ and $I_{S}=N_{p} I_{s d}$ then we can write the following:

$$
I_{p}=N_{P} I_{p h c}-N_{p} I_{s d}\left(\exp \left(\frac{q V_{p}}{N_{S} K n T_{C}}\right)-1\right)
$$

The motor-pump functioning is described by the following equations:

$$
\begin{gathered}
V_{m}=k_{e} \Omega+L \frac{d I_{m}}{d t}+R \cdot I_{m} \\
J \frac{d \Omega}{d t}=k_{b} I_{m}-f \cdot \Omega
\end{gathered}
$$

where:

$k_{e}$ is the counter-electromotive force constant,

$\Omega$ is the angular velocity,

$L$ is the electric inductance,

$R$ is the electric resistance,

$f$ is the motor viscous friction constant,

$k_{b}$ is the torque equation constant,

$J$ is the total inertia moment.

The current $I_{c}$ and the voltage $V_{m}$ are expressed according the switched control variable $u$ as following:

$$
\begin{gathered}
I_{C}=I_{p}-u \cdot I_{m} \\
V_{m}=u \cdot V_{p}
\end{gathered}
$$

Combining the above equations gives:

$$
\left\{\begin{array}{c}
\frac{d V_{P}}{d t}=\frac{1}{C} I_{P}-\frac{1}{C} I_{m} \cdot u \\
\frac{d I_{m}}{d t}=\frac{1}{L} V_{P} \cdot u-\frac{R}{L} I_{m}-\frac{k_{e}}{L} \Omega \\
\frac{d \Omega}{d t}=\frac{k_{b}}{J} I_{m}-\frac{f}{J} \Omega
\end{array}\right.
$$


If we consider the state vector $x=\left[\begin{array}{l}x_{1} \\ x_{2} \\ x_{3}\end{array}\right]$ where: $x_{1}=$ $\mathrm{V}_{\mathrm{p}} ; \mathrm{x}_{2}=\mathrm{I}_{\mathrm{m}}$ and $\mathrm{x}_{3}=\Omega$. Then the model state of the water pumping photovoltaic system presented in Figure (1) can be written as following:

$$
\left\{\begin{array}{c}
\dot{x}_{1}=\frac{1}{C} I_{P}-\frac{1}{C} x_{2} \cdot u \\
\dot{x}_{2}=\frac{1}{L} x_{1} \cdot u-\frac{R}{L} x_{2}-\frac{k_{e}}{L} x_{3} \\
\dot{x}_{3}=\frac{k_{b}}{J} x_{2}-\frac{f}{J} x_{3}
\end{array}\right.
$$

When we suppose that $\alpha\left(x_{1}\right)=\frac{I_{p}}{C}$, then system of equations (9) can be written as follow:

$$
\left\{\begin{array}{c}
\dot{x}_{1}=\alpha\left(x_{1}\right)-\frac{1}{C} x_{2} \cdot u \\
\dot{x}_{2}=\frac{1}{L} x_{1} \cdot u-\frac{R}{L} x_{2}-\frac{k_{e}}{L} x_{3} \\
\dot{x}_{3}=\frac{k_{b}}{J} x_{2}-\frac{f}{J} x_{3}
\end{array}\right.
$$

where $\alpha\left(\mathrm{x}_{1}\right)$ varies depending on the temperature and insolation.

The system non-linearity comes from the exponential function which describes the internal diode behavior in the expression of $I p$. This function prevents to isolate $V p$ by a reliable linearization. Consequently, the dependency between $I p$ and $V p$ constitutes a major obstacle for the command synthesis. To solve this problem, we will use in this paper, a transformation procedure of system in order to writing the model state in multi-model form. That makes it possible to calculate easily a robust control for the system, under different climatic conditions of temperature and insolation.

\section{MULTI-MODEL REPRESENTATION OF THE PHOTOVOLTAIC PUMPING SYSTEM}

\subsection{Multi-model principle}

A multi-model is a system representation composed by a set of simple models easy to manipulate, each of which is valid in a well-defined feature space corresponding to a part of global system's behavior [7]. One degree of validity is associated to each of these models forming a base of model. An activation function which tends to 1 in the feature space and tends to zero outside, specifies the validity degree which estimates the model contribution in the global functioning of the system. The global system's behavior can then be described by the combination of all models of the base. In literature, we can mention three approaches which are largely used for obtaining a multi-model representation: by identification, by linearization and by non-linear sectors transformation [8]. In this paper, we will be interested in the last approach. It is a convex polytopic transformation of scalar functions origin of nonlinearity.

\subsection{Multi-model elaboration}

In order to represent a pumping system in a multi-model form, we will first transform the non-linear model state (10) into a quasi-Linear model with Variable Parameters (quasiLPV) having the following form:

$$
\dot{x}=A(\rho(x, u)) \cdot x+B(\rho(x, u)) \cdot u
$$

It deserves mentioning that the parameters vector $\rho(\mathrm{x}, \mathrm{u})$ will be different in the matrixes $A$ and $B$. However, for simplicity, a single notation will be used in those two matrixes.

Since the state variable $\mathrm{x}_{1}$ can vary depending the temperature and insolation between a non-zero minimum and a maximum value, therefore we can reformulate the system of equation (10) as follow:

$$
\left\{\begin{array}{c}
\dot{x}_{1}=\alpha\left(x_{1}\right) \cdot\left(\frac{x_{1}}{x_{2}}\right)-\frac{1}{C} x_{2} \cdot u \\
\dot{x}_{2}=\frac{1}{L} x_{1} \cdot u-\frac{R}{L} x_{2}-\frac{k_{e}}{L} x_{3} \\
\dot{x}_{3}=\frac{k_{b}}{J} x_{2}-\frac{f}{J} x_{3}
\end{array}\right.
$$

This makes it possible to establish the following quasi-LPV form of the photovoltaic pumping system:

$$
\left[\begin{array}{l}
\dot{x}_{1} \\
\dot{x}_{2} \\
\dot{x}_{3}
\end{array}\right]=\left[\begin{array}{ccc}
\alpha\left(x_{1}\right) / x_{1} & 0 & 0 \\
0 & -R / L & -k_{e} / L \\
0 & k_{b} / J & -f / J
\end{array}\right]\left[\begin{array}{c}
x_{1} \\
x_{2} \\
x_{3}
\end{array}\right]+\left[\begin{array}{c}
-x_{2} / C \\
x_{1} / L \\
0
\end{array}\right] \cdot u
$$

Thereafter, we define the set of non-constant variables in matrixes $A$ and $B$ as the set of premises $V_{z}[9]$ :

$$
\begin{gathered}
V_{z}=\left\{z_{1}(x), z_{2}(x), z_{3}(x)\right\}, \text { where } z_{1}(x)=\alpha\left(x_{1}\right) / x_{1}, \\
z_{2}(x)=-x_{2} / c, z_{3}(x)=x_{1} / L .
\end{gathered}
$$

Each of these premises can be bounded by two extreme values depending on temperature and insolation:

$$
\begin{aligned}
& \underline{z_{1}}<z_{1}(x)<\overline{z_{1}}, \underline{z_{2}}<z_{2}(x)<\overline{z_{2}}, \\
& \underline{z_{3}}<z_{3}(x)<\overline{z_{3}}
\end{aligned}
$$

Then, we apply to these bounded premises a polytopic transformation based on the following lemma [10].

Lemma: Any nonlinear function: $\mathrm{g}(\mathrm{x}): I R \rightarrow I R$ satisfying $\underline{\mathrm{g}}<\mathrm{g}(\mathrm{x})<\overline{\mathrm{g}} ; \forall \mathrm{x}$ can be written as:

$$
g(x)=G_{1}(x) \underline{g}+G_{2}(x) \bar{g}
$$

where:

$$
G_{1}(x)=\frac{\bar{g}-g(x)}{\bar{g}-\underline{g}}, G_{2}(x)=\frac{g(x)-\underline{g}}{\bar{g}-\underline{g}}
$$

and the functions $G_{i}(x), i \in\{1,2\}$ satisfy the convex sum property i.e. $\mathrm{G}_{1}(\mathrm{x})+\mathrm{G}_{2}(\mathrm{x})=1$, and $0<\mathrm{G}_{\mathrm{i}}(\mathrm{x})<1, \forall \mathrm{x}$.

After premises transformation, we obtain: 


$$
z_{i}(x)=F_{i 1}\left(z_{i}(x)\right) \overline{z_{i}}+F_{i 2}\left(z_{i}(x)\right) \underline{z_{i}}, i \in\{1,2,3\}
$$

where:

$$
\begin{gathered}
F_{i 1}\left(z_{i}(x)\right)=\frac{z_{i}(x)-\underline{z_{i}}}{\overline{z_{i}}-\underline{z_{i}}}, F_{i 2}\left(z_{i}(x)\right)=\frac{\overline{z_{i}}-z_{i}(x)}{\overline{z_{i}}-\underline{z_{i}}}, i \in\{1,2,3\} \\
F_{i 1}\left(z_{i}(x)\right)+F_{i 2}\left(z_{i}(x)\right)=1
\end{gathered}
$$

We will denote by $\mathrm{F}_{\mathrm{ij}}$ instead of $\mathrm{F}_{\mathrm{ij}}\left(\mathrm{z}_{\mathrm{i}}(\mathrm{x})\right), \mathrm{j} \in\{1,2\}$.

Our aim consists in evaluating the matrixes $A$ and $B$ from the polytope vertex matrixes which defined from the partitions of the premises that configure in these matrixes.

Considering:

$$
\mathrm{A}\left(\mathrm{z}_{1}(\mathrm{x})\right)=\left[\begin{array}{ccc}
\mathrm{z}_{1}(\mathrm{x}) & 0 & 0 \\
0 & 0 & 0 \\
0 & 0 & 0
\end{array}\right], \mathrm{A}_{0}=\left[\begin{array}{ccc}
0 & 0 & 0 \\
0 & -\mathrm{R} / \mathrm{L} & -\mathrm{k}_{\mathrm{e}} / \mathrm{L} \\
0 & \mathrm{k}_{\mathrm{b}} / \mathrm{J} & -\mathrm{f} / \mathrm{J}
\end{array}\right]
$$

Then the matrix $\mathrm{A}(\rho(\mathrm{x}, \mathrm{u}))$ can be expressed as follow:

$$
A(\rho(x, u))=A\left(z_{1}(x)\right)+A_{0}
$$

When $\mathrm{z}_{1}(\mathrm{x})$ is replaced by its expression of equations (14) and (15), we can obtain the next equation:

$$
A\left(z_{1}(x)\right)=F_{11} \cdot\left[\begin{array}{ccc}
\overline{z_{1}} & 0 & 0 \\
0 & 0 & 0 \\
0 & 0 & 0
\end{array}\right]+F_{12} \cdot\left[\begin{array}{ccc}
\frac{z_{1}}{0} & 0 & 0 \\
0 & 0 & 0 \\
0 & 0 & 0
\end{array}\right]
$$

The next step is to multiply the members of equation (18) by the unit term, $\left(\mathrm{F}_{21}+\mathrm{F}_{22}\right)\left(\mathrm{F}_{31}+\mathrm{F}_{32}\right)$, which gives the equation (19).

$$
\begin{aligned}
& A\left(z_{1}(x)\right)=\mu_{1} A_{1}+\mu_{2} A_{1}+\mu_{3} A_{1}+\mu_{4} A_{1}+\mu_{5} A_{2} \\
& +\mu_{6} A_{2}+\mu_{7} A_{2}+\mu_{8} A_{2}
\end{aligned}
$$

where:

$$
\begin{gathered}
\mu_{1}=F_{21} F_{31} F_{11}, \mu_{2}=F_{21} F_{32} F_{11}, \mu_{3}=F_{22} F_{31} F_{11}, \mu_{4} \\
=F_{22} F_{32} F_{11} \\
\mu_{5}=F_{21} F_{31} F_{12}, \mu_{6}=F_{21} F_{32} F_{12}, \mu_{7}=F_{22} F_{31} F_{12}, \mu_{8} \\
=F_{22} F_{32} F_{12} \\
A_{1}=\left[\begin{array}{ccc}
\overline{Z_{1}} & 0 & 0 \\
0 & 0 & 0 \\
0 & 0 & 0
\end{array}\right] \text { and } A_{2}=\left[\begin{array}{ccc}
Z_{1} & 0 & 0 \\
0 & 0 & 0 \\
0 & 0 & 0
\end{array}\right]
\end{gathered}
$$

Consequently, the matrix $A\left(z_{1}(x)\right)$ is written as a function of two vertex matrixes $A_{1}$ and $A_{2}$.

We proceed in the same way for $B$ in order to express it according to the premises $z_{2}$ and $z_{3}$. We have:

$$
B(\rho(x, u))=B\left(z_{2}(x), z_{3}(x)\right)=\left[\begin{array}{c}
z_{2}(x) \\
z_{3}(x) \\
0
\end{array}\right]
$$

First, $\mathrm{B}(\rho(\mathrm{x}, \mathrm{u}))$ is decomposed with respect to $\mathrm{z}_{2}(\mathrm{x})$, then with respect to $\mathrm{z}_{3}(\mathrm{x})$ :

$$
\begin{aligned}
& B\left(z_{2}(x), z_{3}(x)\right)=F_{21} \cdot F_{31}\left[\begin{array}{c}
\overline{z_{2}} \\
\overline{z_{3}} \\
0
\end{array}\right]+F_{22} F_{31}\left[\begin{array}{c}
\frac{z_{2}}{\overline{z_{3}}} \\
0
\end{array}\right]+ \\
& F_{21} F_{32}\left[\begin{array}{c}
\overline{z_{2}} \\
\frac{z_{3}}{0}
\end{array}\right]+F_{22} F_{32}\left[\begin{array}{c}
\frac{z_{2}}{z_{3}} \\
0
\end{array}\right]
\end{aligned}
$$

After that we multiply the members of the equation (21) by the unit quantity $\left(F_{11}+F_{12}\right)$. So we find the subsequent expression of $B(\rho(x, u))$ :

$$
\begin{aligned}
& B(\rho(x, u))=\mu_{1} B_{1}+\mu_{2} B_{3}+\mu_{3} B_{2}+\mu_{4} B_{4}+\mu_{5} B_{1}+ \\
& \mu_{6} B_{3}+\mu_{7} B_{2}+\mu_{8} B_{4}
\end{aligned}
$$

with:

$$
B_{1}=\left[\begin{array}{c}
\overline{Z_{2}} \\
\overline{Z_{3}} \\
0
\end{array}\right], B_{2}=\left[\begin{array}{c}
Z_{2} \\
\overline{\bar{z}_{3}} \\
0
\end{array}\right], B_{3}=\left[\begin{array}{c}
\overline{Z_{2}} \\
z_{3} \\
\overline{0}
\end{array}\right], B_{4}=\left[\begin{array}{c}
z_{2} \\
\overline{z_{3}} \\
\overline{0}
\end{array}\right]
$$

Therefore, matrix $B(\rho(x, u))$ is then written as a function of four vertex matrixes $B_{1}, B_{2}, B_{3}$ and $B_{4}$.

Finally the state model of the photovoltaic pumping system can be reformulating according the vertex matrixes as following:

$$
\begin{gathered}
\dot{x}=\left(A_{0}+v_{1} A_{1}+v_{2} A_{2}\right) x+\left(v_{3} B_{1}+v_{4} B_{2}+v_{5} B_{3}+\right. \\
\left.v_{6} B_{4}\right) u
\end{gathered}
$$

where:

$$
\begin{gathered}
\dot{x}=\left(A_{0}+v_{1} A_{1}+v_{2} A_{2}\right) x \\
+\left(v_{3} B_{1}+v_{4} B_{2}+v_{5} B_{3}+v_{6} B_{4}\right) u \\
v_{1}=\mu_{1}+\mu_{2}+\mu_{3}+\mu_{4}, v_{2}=\mu_{5}+\mu_{6}+\mu_{7}+\mu_{8}, v_{3} \\
=\mu_{1}+\mu_{5} \\
v_{4}=\mu_{3}+\mu_{7}, v_{5}=\mu_{2}+\mu_{6}, v_{6}=\mu_{4}+\mu_{8}
\end{gathered}
$$

It deserves mentioning that each vertex of the polytope defines a linear subsystem, and that the nonlinearity of the global system is rejected in the weighting functions $v_{\mathrm{i}}$.

\section{SIMULATION RESULTS}

In order to show the reliability of the developed model, we will consider a photovoltaic pumping system which has the following characteristics:

- PVG: PV module: SPM (P) 240-260W

$$
\begin{gathered}
I_{S C}=8.3 \mathrm{~A}, V_{m p}=31.58 \mathrm{~V}, I_{m p}=7.6 \mathrm{~A} ; V_{O C}= \\
36.6 \mathrm{~V}, \alpha_{0}=0.05 \% /{ }^{\circ} \mathrm{C}, N_{S}=60 . \\
\beta_{0}=-0.34 \% /{ }^{\circ} \mathrm{C}, \mathrm{NOCT}=45 \mp 2^{\circ} \mathrm{C} .
\end{gathered}
$$


Motor-pump DC: It is characterized by a nominal functioning point:

$$
\mathrm{u}_{\mathrm{n}}=24 \mathrm{~V} \text { and } \mathrm{I}_{\mathrm{n}}=12 \mathrm{~A} ; \omega_{\mathrm{n}}=2000 \mathrm{tr} / \mathrm{mn} \text {. }
$$

Its parameters are: $\mathrm{R}=1.072 ; \mathrm{L}=0.05 \mathrm{H} ; \mathrm{f}=$ $8814.10^{-7}$ N.m. $\frac{\mathrm{s}}{\mathrm{rd}} ; \mathrm{k}_{\mathrm{e}}=0.5 ; \mathrm{k}_{\mathrm{b}}=0.1$; $476.10^{-6} \mathrm{Kg} . \mathrm{m}^{2}$ and $\mathrm{C}=4.7 \mathrm{mF}$.

Concerning the experimental conditions, we choose the maximum and minimum values of temperature and irradiance as follow:

$$
\begin{gathered}
\mathrm{G}_{\max }=1200 \mathrm{~W} / \mathrm{m}^{2} ; \mathrm{G}_{\min }=400 \mathrm{~W} / \mathrm{m}^{2} ; \mathrm{T}_{\max } \\
=60^{\circ} \mathrm{C} ; \mathrm{T}_{\min }=0^{\circ} \mathrm{C} .
\end{gathered}
$$

The extreme values of the PVG voltage $V_{p}$ and the current $I_{p}$ are calculated according to the temperature and irradiance by the following formulas [11-12]:

$$
\begin{gathered}
\mathrm{V}_{\mathrm{p}}=\mathrm{V}_{\mathrm{mp}}\left[1+0.0539 \mathrm{Ln}\left(\frac{\mathrm{G}}{\mathrm{G}_{0}}\right)\right]+\beta_{0}\left(\mathrm{~T}_{\mathrm{C}}-\mathrm{T}_{\mathrm{C} 0}\right) \\
\mathrm{I}_{\mathrm{p}}=\mathrm{I}_{\mathrm{ph}}-\mathrm{I}_{\mathrm{S}}\left(\mathrm{e}^{\frac{\mathrm{qV}_{\mathrm{P}}}{\mathrm{N}_{\mathrm{S}} \mathrm{KT}_{\mathrm{c}}}}-1\right)
\end{gathered}
$$

where:

$$
\mathrm{T}_{\mathrm{C}}=\mathrm{T}_{\mathrm{a}}+\left[\frac{\mathrm{NOCT}-20}{800}\right] \cdot \mathrm{G}
$$

with:

$\mathrm{T}_{\mathrm{C}}$ : Temperature of the PV module;

$\mathrm{T}_{\mathrm{a}}$ : is the ambient temperature;

$\mathrm{T}_{\mathrm{C} 0}$ : Temperature of the PV module at STC;

NOCT: Nominal Operating cell Temperature;

$\mathrm{V}_{\mathrm{mp}}$ : The maximum PVG voltage under standard conditions; $\alpha_{0}$ : Coefficient of current according the temperature;

$\beta_{0}$ : Coefficient of voltage according the temperature;

$\mathrm{T}_{0}=298^{\circ} \mathrm{k} ; \mathrm{G}_{0}=1000 \mathrm{Watt} / \mathrm{m}^{2}$.

The ideality factor $n$ depends on PV cell technology and can be chosen in [13].

$\mathrm{I}_{\mathrm{ph}}$ is expressed according temperature and insolation by the following equation [14]:

$$
\mathrm{I}_{\mathrm{ph}}=\frac{\mathrm{G}}{\mathrm{G}_{0}}\left(\mathrm{I}_{\mathrm{SC}}+\alpha_{0}\left(\mathrm{~T}_{\mathrm{C}}-\mathrm{T}_{\mathrm{C} 0}\right)\right)
$$

and $\mathrm{I}_{\mathrm{S}}$ is given by the equation (27).

$$
\mathrm{I}_{\mathrm{S}}=\mathrm{I}_{\mathrm{S} 0}\left(\mathrm{~T}_{\mathrm{C}} / \mathrm{T}_{\mathrm{C} 0}\right)^{3} \mathrm{e}^{\frac{\mathrm{qEg}}{\mathrm{N}_{\mathrm{S}} \mathrm{nK}}\left(\frac{1}{\mathrm{~T}_{\mathrm{C} 0}}-\frac{1}{\mathrm{~T}_{\mathrm{C}}}\right)}
$$

where $E g$ is the bang-gap energy of the semiconductor used in the cell, and $I_{S 0}$ is given by:

$$
\mathrm{I}_{\mathrm{S} 0}=\frac{\mathrm{I}_{\mathrm{SC}}}{\mathrm{e}^{\frac{\mathrm{qV} \mathrm{OC}_{\mathrm{S}}}{\mathrm{NKT}_{\mathrm{C} 0}}}-1}
$$

After calculating the weighting functions $\gamma_{\mathrm{i}}$ and the vertex matrixes relating to the model developed according to the preceding parameters, this latter is simulated in Matlab environment. The result is given in the following figure, which illustrate the evolution of system's PVG voltage and that of model PVG voltage for different temperature and irradiance pairs chosen arbitrarily, and for two values of command randomly selected.
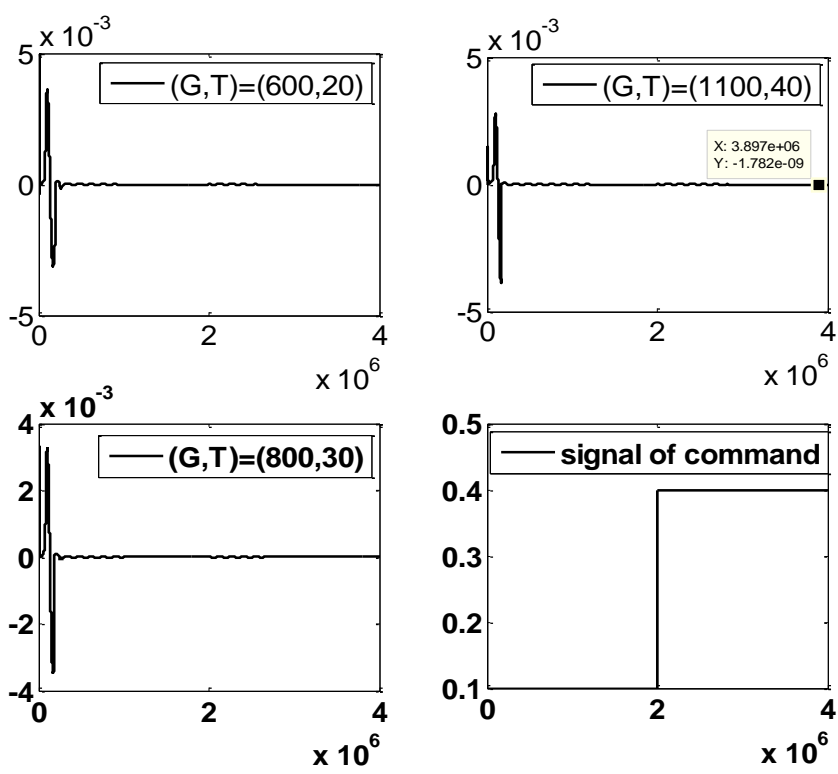

Figure 2. Evolution of the system's PVG voltage and that of the model's PVG voltage, for two different values of command and different couples of temperature and irradiance
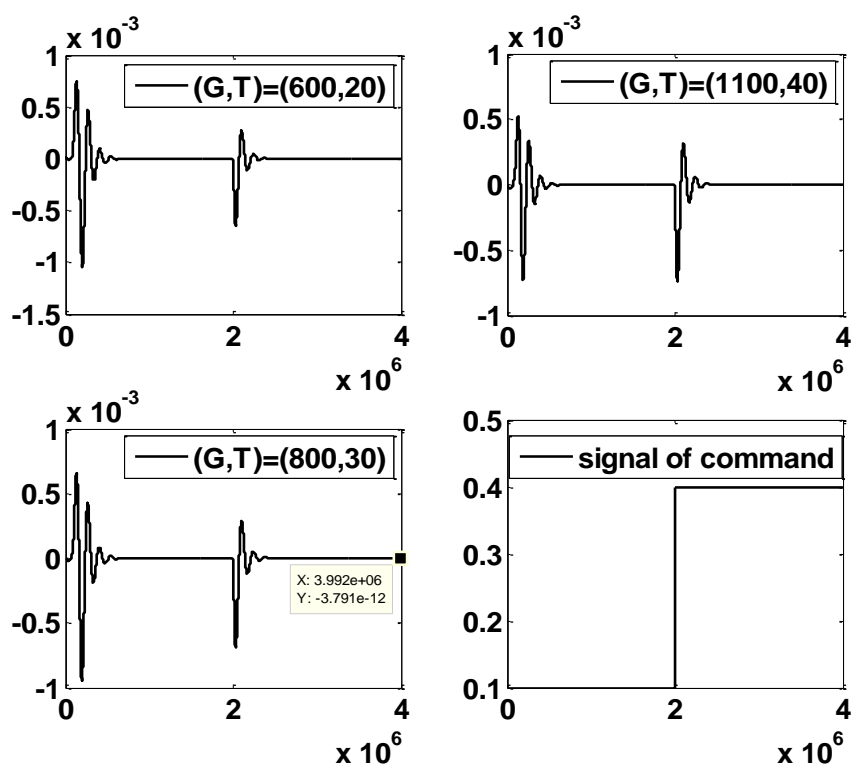

Figure 3. Evolution of the angular velocity $\Omega$ of the system and that of the model. for two different values of command and different couples of temperature and irradiance

We note that the error between voltage generate by the system's PVG and that generate by the model's PVG under diverse climatic conditions of temperature and illumination, and for different command decreases up to $10^{-9}$. This result leads to a model able to imitate with a great precision the PVG voltage of the system.

To test the model aptitude to replicate the behavior of all system state variables, we have simulated the angular velocity $\Omega$ of the system and that of the model. As well as the motor 
current $I_{m}$ of the system and that of the model. The simulation result is given respectively in Figures 3 and 4.
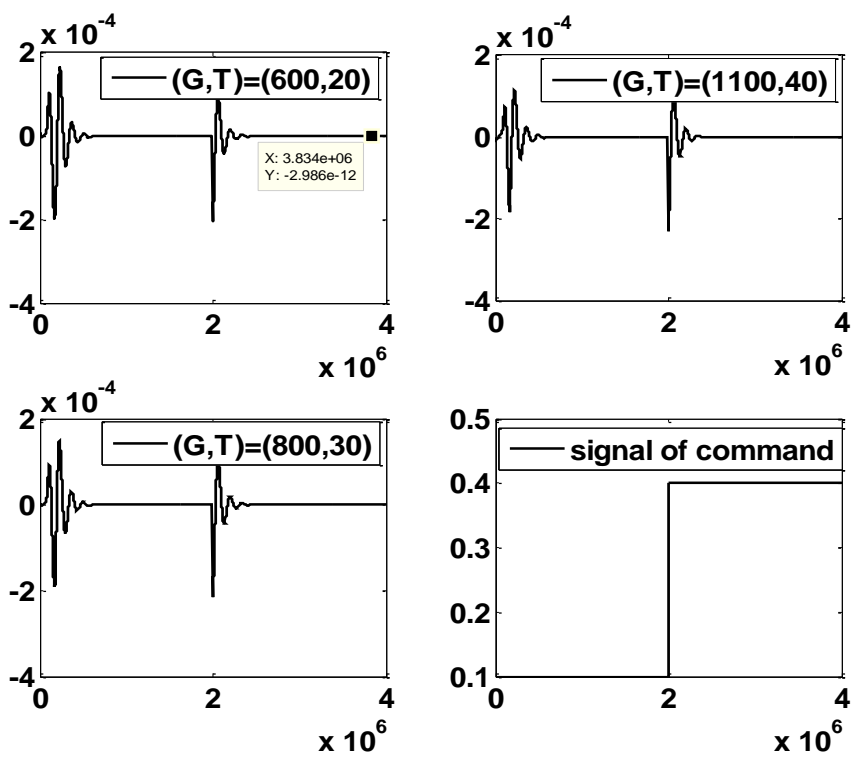

Figure 4. Evolution of motor current $I_{m}$ of the system and that of the model, for two different values of command and different couples of temperature and irradiance

We notice according to the simulation results given in Figures 3 and 4 , that the modeling error reaches $10^{-12}$. These results demonstrate the model success to reproduce with high precision the conduct of the system state variables. That attests again the high quality of the elaborate model.

\section{CONCLUSION}

The performance of a Photovoltaic pumping system highly depends on the weather conditions, such as temperature and insolation, so does the performance of the PV generator degrade with increasing temperature and decreasing insolation. To provide water continuously throughout the year, a PV pumping system must be led by intelligent control which depends heavily on the quality of the system model. The model must guarantee a correct description of the expected variation in the system. This objective is reached by the model structure proposed in this paper. Indeed, we have developed an accurate model that represents the behavior of the system under different climatic conditions of temperature and insolation. The multi-model approach is used to represent the system by a set of simple models, which calculates according the extreme values of temperature and insolation. The modeling begins with the establishment of the quasi-LPV form, then the identification of the premise variables, next the premise decomposition and finally the development of matrixes and weighting functions. The simulation results of the method proved the good quality of the established model. Therefore we recommend for future researches to control the system with a multi-model command based on the elaborated model. Indeed, each model of the base can allow the generation of a partial controller which is used to derive the global control to be applied to the system. The simplicity of the eight models can involves a powerful and easy control law which can be implemented in real time.
In perspective, this work will be continued with a practical implementation of the model by an Arduino board for increasing the efficiency of the system to extract the maximum energy.

\section{ACKNOWLEDGMENT}

We would like to thank all the people who contributed in some way to this work which was supported by the Center of Researches and Technologies of Energy of Borj Cedria, Tunis and Ministry of Higher Education and Scientific Research

\section{REFERENCES}

[1] Pa, J., Gaurag, S.H. (2013). Modeling and Simulation of Solar Photovoltaic Module using Matlab/Simulink. International Journal of Research in Engineering and Technology, 02(03). https://doi.org/10.15623/ijret.2013.0203003

[2] Abdulkadir, M., Samosir, A.S.A., Yatim, H.M. (2013). Modeling and simulation of a solar photovoltaic system, its dynamics and transient characteristics in LABVIEW. International Journal of Power Electronics and Drive System (IJPEDS), 3(2): 185-192.

[3] Hongmei, T., Mancilla-Davida, F., Kevin, E., Eduard, M., Peter, J. (2012). A cell- to - module -to-a cell detailed model for photovoltaic panels. Solar Energy, 86(9): 2695-2706.

https://doi.org/10.1016/j.solener.2012.06.004

[4] Ravinder, K.K., Shimib, S.L., Chatterjib, S., Fahim, A. (2014). Modelling of solar PV module and maximum power point tracking using Anfis. Renew. Sustain. Energy Rev., 33: 602-612. https://doi.org/10.1016/j.rser.2014.02.014

[5] Ait-Cheikh, S.M. (2007). Etude, Investigation et conception d'algorithmes de commande appliqués aux systèmes photovoltaïque. $\mathrm{PhD}$ thesis. Ecole Nationale Polytechnique.

[6] Petibon, S. (2009). Nouvelles architectures distribuées de gestion et de conversion de l'énergie pour les applications photovoltaïques. Ph.D. thesis, Toulouse university, France.

[7] Smith, R.M.T.A. (1997). Johansen Multiple Multimodel Approachs to Modelling and Control. Edition, Taylor and Francis.

[8] Nesrine, E. (2010). Approche neuronale de la representation et de la commande multimodèle de processus complexe. Ph.D. Thesis. Ecole Doctorale Science pour l'Ingénieur Université Lille, France.

[9] Anca, M.N. (2010). Analyse et synthèse de multimodèle pour le diagnostic. Application à une station d'épuration. Ph.D. Thesis. National Polytechnic Institute of Lorraine, France.

[10] Kazuo, T., Hua, O.W. (2001). Fuzzy Control Systems Design and Analysis: A Linear Matrix Inequality Approach. A Wiley-Interscience Publication.

[11] Belhaj, M., Benouaz, T., Cheknane, A., Bekkouche, S.M.A. (2010). Estimation de la puissance maximale produite par un générateur photovoltaique. Revue des Energies Renouvelables, 13(2): 256-257.

[12] Habbati, B., Ramdani, Y., Moulay, F. (2014). A detailed modeling of photovoltaic module using MATLAB. 
NRIAG Journal of Astronomy and Geophysics, 3: 53-61. https://doi.org/10.1016/j.nrjag.2014.04.001

[13] Bogdan, S.B., Salameh, Z.M. (1996). Methodology for optimally sizing the combination of a battery bank and $\mathrm{PV}$ array in a wind/PV hybrid system. IEEE Transactions on Energy Conversion, 11(2): 367-375.
[14] Tsai, H.L., Tu, C.S., Su, Y.J. (2008). Development of generalized photovoltaic model using MATLAB/Simulink. Proceedings of the World Congress on Engineering and Computer Science. San Francisco, USA. 